\title{
$\beta$-catenin knockdown inhibits pituitary adenoma cell proliferation and invasion via interfering with AKT and gelatinases expression
}

\author{
CHENGCHENG ZHAO ${ }^{1,2,3}$, MENG ZHANG ${ }^{2,3}$, WENLAN LIU ${ }^{2,4}$, \\ CHUANFANG WANG ${ }^{2,3}$, QIUSHENG ZHANG ${ }^{2,3}$ and WEIPING LI ${ }^{2,3}$ \\ ${ }^{1}$ Guangzhou Medical University, Guangzhou, Guangdong 510182; ${ }^{2}$ Shenzhen Key Laboratory of Neurosurgery, \\ ${ }^{3}$ Department of Neurosurgery, ${ }^{4}$ The Central Laboratory, Shenzhen Second People's Hospital, \\ Shenzhen, Guangdong 518035, P.R. China
}

Received November 13, 2014; Accepted January 7, 2015

DOI: $10.3892 /$ ijo.2015.2862

\begin{abstract}
Pituitary adenomas are among the most prevalent forms of intrinsic brain tumors. Although most pituitary adenomas are benign, some of them may become invasive and cause significant mass effect and hormonal dysfunction. We have previously shown that $\beta$-catenin is overexpressed in human pituitary adenomas and its level correlates to tumor grades. In the present study, we further investigated the role of $\beta$-catenin in pituitary adenoma cell proliferation and invasion in vitro. Stable $\beta$-catenin knockdown pituitary adenoma cell line was created by transfecting mouse growth hormone pituitary adenoma GT1.1 cells with $\beta$-catenin shRNA plasmid. Cell proliferation and invasion were assessed using CCK-8 kit and Transwell assay, respectively. Our data demonstrated that knockdown of $\beta$-catenin with shRNA significantly inhibited the proliferation and invasion of GT1.1 cells. In $\beta$-catenin shRNA transfected cells, the expression of AKT, STAT3, cyclin D1 and CDK4 were significantly suppressed, which accounted for the observed growth retardation following $\beta$-catenin shRNA transfection. Moreover, $\beta$-catenin shRNA transfection led to a drastic reduction in MMP-2/9 secretion into the conditioned media, which might be responsible for the reduced invasiveness of $\beta$-catenin shRNA-transfected pituitary adenoma cells. These results indicate that $\beta$-catenin may regulate the expression of AKT, STAT3, cyclin D1, CDK4 and MMP-2/9 to promote pituitary adenoma cell proliferation and invasion.
\end{abstract}

\section{Introduction}

Pituitary adenomas represent $\sim 10-25 \%$ of the intrinsic central nervous system (CNS) tumors (1). Although most pituitary

Correspondence to: Professor Weiping Li, Department of Neurosurgery, Shenzhen Second People's Hospital/Shenzhen University First Affiliated Hospital, Shenzhen, Guangdong 518035, P.R. China E-mail: liweiping60@126.com

Key words: $\beta$-catenin, pituitary adenoma, proliferation, invasion, shRNA tumors are benign and slow growing, some of them are aggressive and can cause morbidity and premature mortality. Pituitary adenomas exhibit a wide range of clinical behavior including brain structure compression and abnormal pituitary hormone production (2). A number of pituitary adenomas are invasive and expand to adjacent tissues and structures such as sphenoid, cavernous sinus and dura mater. These tumors are often rapidly growing, readily recurring after surgical resection, resistant to radiation and pharmacotherapy, and are thus a great medical challenge (3). Despite extensive research efforts, how pituitary adenomas become rapidly growing and invasive remains to be elucidated.

The Wnt $/ \beta$-catenin signaling pathway plays a critical role in pituitary development and organogenesis via regulating the transcription factors Pitx2, Nr5a1 (Sf1) and Tcf712 (Tcf4) (4-6). This pathway has been demonstrated to control the maintenance of progenitor/stem cells and secure the balance between stem cell differentiation and self-renewal in various tissues and organs $(7,8)$. Deregulation of this balance leads to a number of cancers (9-12), and evidence for a possible role of pituitary progenitor/stem cells in the genesis of pituitary tumors has been shown in an animal study (13). In a previous study, we found that $\beta$-catenin was overexpressed in human pituitary adenomas, and its expression level correlated to tumor invasion (14). However, the underlying mechanisms remain to be elucidated.

In normal cells, $\beta$-catenin is either bound to E-cadherin to maintain cell adhesion or resides unbound in the cytoplasm (15). Cytoplasmic $\beta$-catenin binds to adenomatous polyposis coli (APC), axin1 and glycogen synthase kinase- $3 \beta$ (GSK-3 $\beta$ ), resulting in $\beta$-catenin phosphorylation which promotes its degradation $(8,16-18)$. The accumulation of $\beta$-catenin in the cytoplasm leads to its translocation into the nucleus and binding to TCF/LEF transcription factors to regulate several target genes (19). Increasing evidence suggests that excessive accumulation of $\beta$-catenin is involved in tumor invasion and proliferation (20-22). In human colorectal cancer, $\beta$-catenin expression levels are found to be associated with aggressive morphological features, epithelial-mesenchymal transition and a poor prognosis (23). In human astrocytomas, overexpressed $\beta$-catenin binds to a Lef/Tcf protein to promote cell proliferation. However, little is known about the down- 
stream molecules that are activated by $\beta$-catenin in invasive pituitary adenomas (24).

In the present study, we created a stable $\beta$-catenin knockdown pituitary cell line to investigate the role of $\beta$-catenin and its downstream molecules in the tumorgenesis of pituitary adenomas. Our results showed that knockdown of $\beta$-catenin with shRNA significantly inhibited pituitary adenoma cell proliferation and migration, and this change was accompanied by decreased expression of AKT, STAT3, cyclin D1, CDK4, MMP-2 and MMP-9. Our results suggest that $\beta$-catenin may regulate multiple downstream molecules to enhance pituitary adenoma cell proliferation and invasion.

\section{Materials and methods}

Cell culture. The mouse growth hormone pituitary adenoma cell line GT1.1 (purchased from the China Academy of Medical Sciences Cell Culture Center, Beijing, China) was cultured in DMEM-F12 medium (Gibco, Carlsbad, CA, USA) supplemented with $10 \%$ fetal bovine serum (FBS; Gibco) and maintained at $37^{\circ} \mathrm{C}$ in a humidified atmosphere with $5 \% \mathrm{CO}_{2}$.

Plasmid transfection with $\beta$-catenin shRNA. For $\beta$-catenin knockdown experiment, shRNA plasmid (sc-29210-SH) and copGFP control plasmid (sc-108083) were purchased from Santa Cruz Biotechnology (Santa Cruz, CA, USA). According to the manufacturer's instructions, the cells at $70-80 \%$ confluence were subjected to shRNA plasmid transfection using transfection reagent (Santa Cruz Biotechnology). Puromycin $(5 \mu \mathrm{g} / \mathrm{ml})$ was used to kill non-transfected cells and transfection efficiency was checked under a fluorescence microscope. More than $90 \%$ of the cells showed green fluorescence (Fig. 1A) and were used for the indicated experiments.

Total RNA extraction and real-time quantitative polymerase chain reaction $(R T-q P C R)$. Total RNA was extracted using the RNAiso Plus (Takara Bio, Shiga, Japan). Total RNA $(2 \mu \mathrm{g})$ was reverse transcribed using PrimeScript ${ }^{\mathrm{TM}}$ RT Master Mix (Takara Bio) according to manufacturer's instructions. The primer sequences used for RT-qPCR were as follows: mouse $\beta$-catenin: 5'-TGG CAA TCA AGA GAG CAA GC-3' (forward) and 5'-GAC AGA CAG CAC CTT CAG CA-3' (reverse); mouse $\beta$-actin: 5'-GGA GAT TAC TGC CCT GGC TCC TA-3' (forward) and 5'-GAC TCA TCG TAC TCC TGC TTG CTG-3' (reverse); mouse MMP-2: 5'-TGT GTT CTT TGC AGG GAA TGA AT-3' (forward) and 5'-TGT CTT CTT GTT TTT GCT CCA GTT A-3' (reverse); mouse MMP-9: 5'-CCT CTG GAG GTT CGA CGT GA-3' (forward) and 5'-TAG GCT TTC TCT CGG TAC TGG AA-3' (reverse). RT-qPCR was performed on ABI 7300 Real-Time PCR system (Applied Biosystems, Foster City, CA, USA) using the SYBR Premix Ex Taq kit (Takara Bio) following the cycling profile: $95^{\circ} \mathrm{C}$ for $30 \mathrm{sec}$, followed by 40 cycles of amplification $\left(95^{\circ} \mathrm{C}\right.$ for $5 \mathrm{sec}$ and $60^{\circ} \mathrm{C}$ for $20 \mathrm{sec}$ ). The target mRNA expression levels were normalized to $\beta$-actin. The $\mathrm{Ct}$ value for each sample was calculated using the $\Delta \Delta \mathrm{Ct}$-method and results were expressed as $2^{-\Delta \Delta C T}$.

Western blot analysis. The cells were lysed in RIPA lysis buffer (sc-364162; Santa Cruz Biotechnology) containing
$10 \mu \mathrm{l} / \mathrm{ml}$ protease inhibitor cocktail (sc-364162; Santa Cruz Biotechnology) and incubated on ice for $30 \mathrm{~min}$. Protein concentration was quantified using the BCA protein assay kit (Pierce, Rockford, IL, USA). Protein samples (30 $\mu \mathrm{g} / \mathrm{lane})$ were diluted in $5 \mathrm{X}$ SDS-PAGE sample loading buffer and electrophoretically separated on $10 \%$ SDS-PAGE gel. After transferring onto polyvinylidene difluoride membranes (Millipore, Bedford, MA, USA), the membranes were blocked in $5 \%$ non-fat skim milk and incubated overnight at $4^{\circ} \mathrm{C}$ in primary antibodies. After being washed 3 times for $5 \mathrm{~min}$, membranes were incubated in suitable secondary antibodies (1:5,000; Millipore) for $1 \mathrm{~h}$ at room temperature. Signals were detected using the Immobilon Western Chemiluminescent HRP Substrate (Millipore) and Alliance Imaging systems (Uvitec, Cambridge, UK). Antibodies were obtained as follows: primary antibodies, monoclonal rabbit anti-mouse $\beta$-catenin (1:1000; Abcam, Cambridge, UK), monoclonal rabbit antimouse STAT3 (1:1,000; Cell Signaling Technology, Beverly, MA, USA), monoclonal rabbit anti-mouse cyclin D1 (1:800; Millipore), monoclonal rabbit anti-mouse CDK4 (1:200; Santa Cruz Biotechnology), monoclonal rabbit anti-mouse $\beta$-tubulin (1:500; Abcam); secondary antibody, goat anti-rabbit IgG, peroxidase conjugated (1:5,000; Millipore).

Gelatin zymography. MMP-2 and MMP-9 levels in culture media and in cellular extracts were examined using gelatin zymography assay. GT1.1 cells were seeded on 6-well plates at $1 \times 10^{6}$ cells/well and incubated at $37^{\circ} \mathrm{C}$ in $2 \mathrm{ml}$ of serumfree DMEM-F12 for $24 \mathrm{~h}$ before collecting the supernatants. The cells were lysed in RIPA lysis buffer as described above. Protein $(30 \mu \mathrm{g})$ or $20 \mu \mathrm{l}$ supernatant per lane was mixed with equal volume of $2 \mathrm{X}$ sample buffer $(62.5 \mathrm{mM}$ Tris- $\mathrm{HCl}$ containing $10 \%$ glycerol, $0.00125 \%$ bromophenol blue and $12 \%$ SDS) without reducing agent and were electrophoresed on a $10 \%$ sodium dodecyl sulfate-polyacrylamide gel with $0.1 \%$ gelatin (Invitrogen, Grand Island, NY, USA) incorporated as a substrate for gelatinolytic proteases under non-reducing condition at $120 \mathrm{~V}$ for $2 \mathrm{~h}$. Gels were washed two times in $25 \mathrm{ml} / \mathrm{l}$ Triton X-100 for $30 \mathrm{~min}$ and subsequently incubated at $37^{\circ} \mathrm{C}$ for $36 \mathrm{~h}$ in reaction buffer $(50 \mathrm{mmol} / \mathrm{l}$ Tris- $\mathrm{HCl}, \mathrm{pH} 7.6,50 \mathrm{mmol} / \mathrm{l}$ $\left.\mathrm{NaCl}, 5 \mathrm{mmol} / \mathrm{l} \mathrm{CaCl}_{2}, 1 \mu \mathrm{mol} / \mathrm{I} \mathrm{ZnCl}_{2}, 0.02 \% \mathrm{Brij}-35\right)$, and stained with $0.5 \%$ coomassie brilliant blue R-250 (Bio-Rad Laboratories, Hercules, CA, USA). Gelatinolytic activity was measured as clear areas using Gel Doc XR+ imaging system (Bio-Rad Laboratories).

Cell proliferation assay. GT1.1 cells were seeded into 96-well plates at 2,000 cells/well and incubated for $8 \mathrm{~h}$ to allow cell adhesion. Cell proliferation was assessed at indicated incubation time-points after cell adhesion using Cell Counting kit-8 (Dojindo Laboratories, Kumamoto, Japan). All measurements were conducted in triplicate.

Transwell assay. For tumor invasion assay, cold serum-free DMEM-F12 medium was mixed with Matrigel (1:5; BD Biosciences, NJ, USA). The upper chambers ( $8 \mu \mathrm{m}$ pore size; Corning, Franklin Lakes, NY, USA) were coated with $100 \mu \mathrm{l}$ Matrigel mixture and allowed to solidify at $37^{\circ} \mathrm{C}$ for $4 \mathrm{~h}$, then $2 \times 10^{5}$ cells were seeded into the upper chambers. The lower chamber contained $1 \mathrm{ml}$ DMEM-F12 and 10\% FBS as 
A


Figure 1. $\beta$-catenin is downregulated in GT1.1 cells transfected with $\beta$-catenin shRNA plasmid. (A) GT1.1 cells were transfected with copGFP control plasmid to evaluate the efficiency of stable transfection. Representative images showed $>90 \%$ of the cells were positively transfected as indicated by the expression of the reporter gene GFP by using fluorescence microscopy (magnification, x100, left: phase contrast, right: green fluorescence). (B) After stable transfection with $\beta$-catenin shRNA, $\beta$-catenin mRNA expression was detected by RT-qPCR. $\beta$-catenin mRNA expression was significantly decreased in $\beta$-catenin shRNA transfected cells when compared with untreated and shRNA control cells. Data are expressed as mean $\pm \mathrm{SEM}$, $\mathrm{n}=3$, $\mathrm{P}<0.05$ vs. untreated and control shRNA groups. (C) Western blot was used to assess the $\beta$-catenin protein levels in GT1.1 cells. $\beta$-catenin protein levels were significantly reduced in $\beta$-catenin shRNA transfected cells when compared with untreated and shRNA control cells. Data are expressed as mean $\pm \mathrm{SEM}, \mathrm{n}=3$, $\mathrm{P}<0.05$ vs. untreated and control shRNA groups. $\beta$-tubulin served as a loading control.

a chemoattractant. After 24-h incubation, non-invaded cells in the upper chambers were removed with a cotton swab, and invaded cells were fixed in $70 \%$ methanol. Fixed cells were stained with $0.1 \%$ crystal violet for $10 \mathrm{~min}$, washed twice with PBS and counted (5 random x100 fields/well). Data were expressed as the mean cell number of three independent experiments.

Statistical analysis. The statistical analyses were performed using SPSS 16.0 statistics software. All data are presented as means \pm SEM. The significance of difference between the groups was determined by using a one-way analysis of variance (ANOVA) followed by Tukey's post hoc test. A value of $\mathrm{P}<0.05$ was considered as a statistically significant difference.

\section{Results}

$\beta$-catenin is downregulated in GT1.1 cells transfected with $\beta$-catenin shRNA plasmid. To determine whether $\beta$-catenin affects the proliferation and invasion of pituitary adenoma, we created a stable-knockdown cell line by transfecting $\beta$-catenin shRNA plasmid into GT1.1 cells. The efficiency of stable transfection in GT1.1 cells was examined by fluorescent microscopy, and $>90 \%$ of the cells were positively transfected as indicated by the expression of the reporter gene GFP (Fig. 1A). In addition, real-time RT-PCR and western blot analysis were performed to determine the efficacy of $\beta$-catenin shRNA in knocking down $\beta$-catenin. Fig. 1B shows that $\beta$-catenin shRNA transfection significantly decreased $\beta$-catenin mRNA expression (57\% reduction), while control shRNA had no effect when compared with untreated cells. Accordingly, $\beta$-catenin protein levels were also significantly reduced in $\beta$-catenin shRNA transfected cells (Fig. 1C). These results clearly indicate that we successfully created a stable $\beta$-catenin knockdown pituitary adenoma cell line by shRNA plasmid transfection.

Knockdown of $\beta$-catenin inhibits GT1.1 cell proliferation. Cell Counting kit-8 (CCK-8) assay was performed to assess the effect of $\beta$-catenin knockdown on cell proliferation. The 


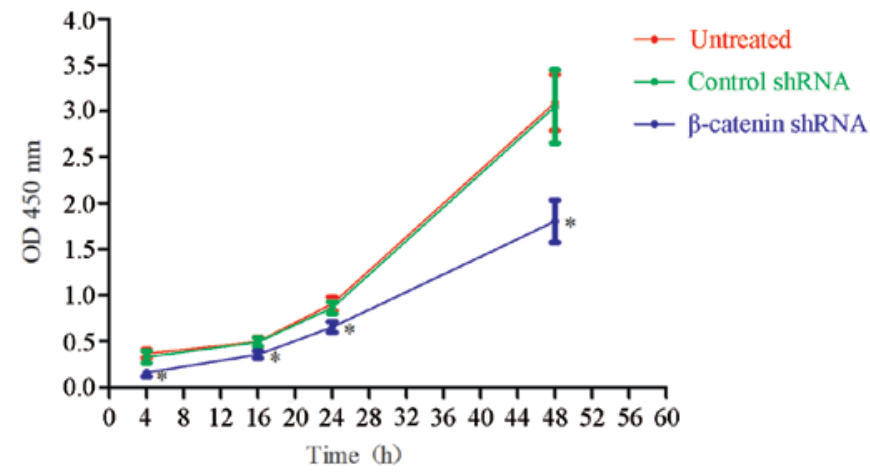

Figure 2. Knockdown of $\beta$-catenin inhibits the proliferation of GT1.1 cells. The GT1.1 cell proliferation was assessed by the CCK-8 assay. After stable transfection with $\beta$-catenin shRNA, GT1.1 cell proliferation was significantly inhibited. The results were expressed as mean $\pm \mathrm{SEM}, \mathrm{n}=3,{ }^{*} \mathrm{P}<0.05$ vs. untreated and control shRNA groups.

cells were seeded at a density of 2,000 cells/well in 96-well plates and were allowed to attach for $8 \mathrm{~h}$ before measuring cell proliferation at 4, 16, 24 and $48 \mathrm{~h}$. As shown in Fig. 2, $\beta$-catenin shRNA transfection significantly, but not completely, inhibited GT1.1 cell proliferation when compared with control shRNA $(\mathrm{P}<0.05)$. As expected, there was no difference between control shRNA-treated and untreated cells. This result indicated that knockdown of $\beta$-catenin significantly inhibited GT1.1 cell proliferation.

Knockdown of $\beta$-catenin attenuates pituitary adenoma cell invasion. Transwell invasion assay was applied to determine whether $\beta$-catenin knockdown could inhibit the invasion of GT1.1 cells. As shown in Fig. 3A, $\beta$-catenin shRNA transfection significantly reduced the number of cells that migrated to the lower surface of the inserts compared with control shRNAtreated cells and untreated cells $(\mathrm{P}<0.05)$, and there was no difference between control shRNA-treated and untreated cells. As $\beta$-catenin shRNA transfection inhibited cell proliferation, there was a possibility that the reduced number of $\beta$-catenin shRNA-treated cells detected in the lower surface of the insert might result from inhibited proliferation. To exclude this possibility, we inhibited cell proliferation with $25 \mu \mathrm{g} / \mathrm{ml}$ mitomycin half an hour before assessing invasion. Similarly, a significant reduction in cell invasion was observed for $\beta$-catenin shRNA transfected cells $(\mathrm{P}<0.05)$, and there was no difference between control shRNA-treated and untreated cells (Fig. 3B). The results showed that knockdown of $\beta$-catenin inhibited pituitary adenoma cell invasion.

Knockdown of $\beta$-catenin inhibits the expression STAT3 and AKT in GT1.1 cells. To further understand how $\beta$-catenin knockdown inhibited pituitary adenoma cell proliferation
A

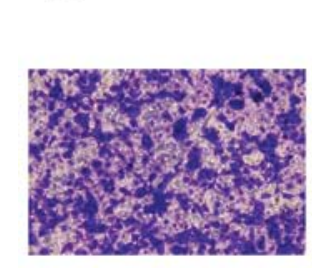

Untreated
No mitomycin

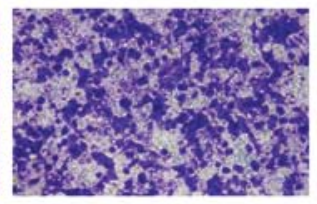

Control shRNA

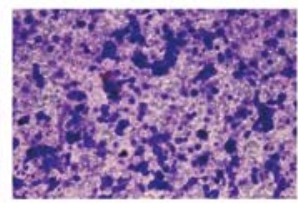

B-catenin shRNA
B

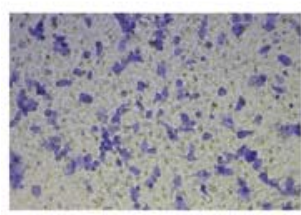

Untreated
Mitomycin

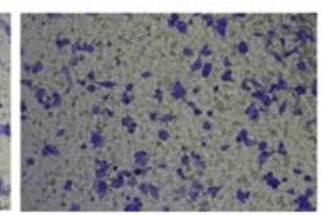

Control shRNA

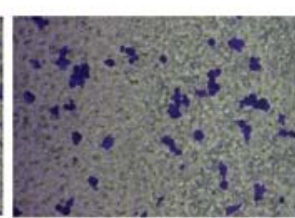

$\beta$-catenin shRNA
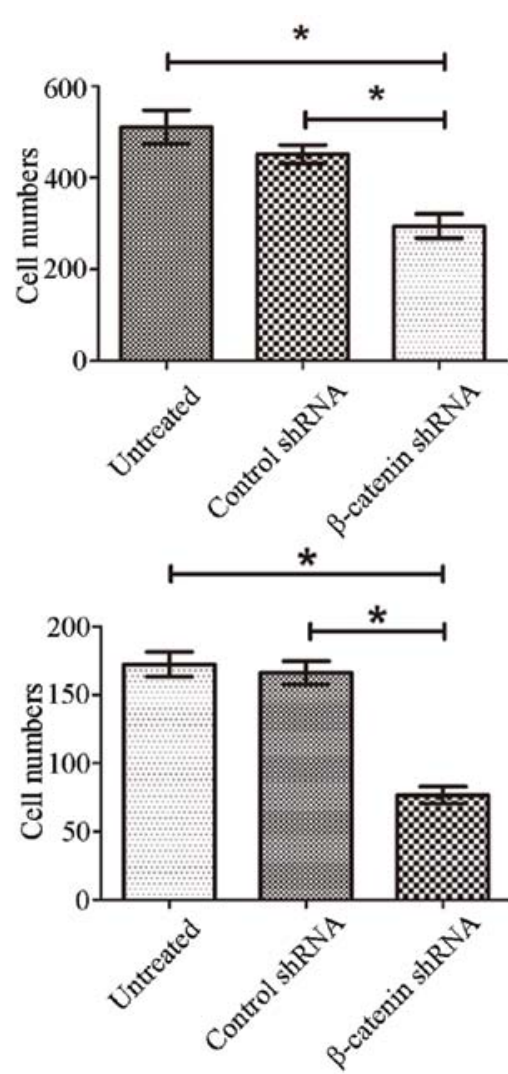

Figure 3. Knockdown of $\beta$-catenin attenuates GT1.1 cell invasion. The GT1.1 cell invasion was assessed by Transwell assay. (A) Representative images (left panel) and quantitative analyses of cell count in the lower surface of the insert (right panel) showed that $\beta$-catenin shRNA transfection significantly reduced the number of cells that migrated to the lower surface of the inserts compared with control shRNA-treated cells and untreated cells. (B) The cell proliferation was inhibited by using mitomycin. Representative images (left panel) and quantitative analyses of cell count in the lower surface of the insert (right panel) showed that the invasive ability of $\beta$-catenin shRNA-transfected cell was also reduced compared with untreated and control shRNA cells. The invaded cells were fixed in $70 \%$ methanol. Images were captured under a light microscope with magnification $\mathrm{x} 200$. The results are expressed as mean $\pm \mathrm{SEM}, \mathrm{n}=3$, ${ }^{*} \mathrm{P}<0.05$ vs. untreated and control shRNA groups. 

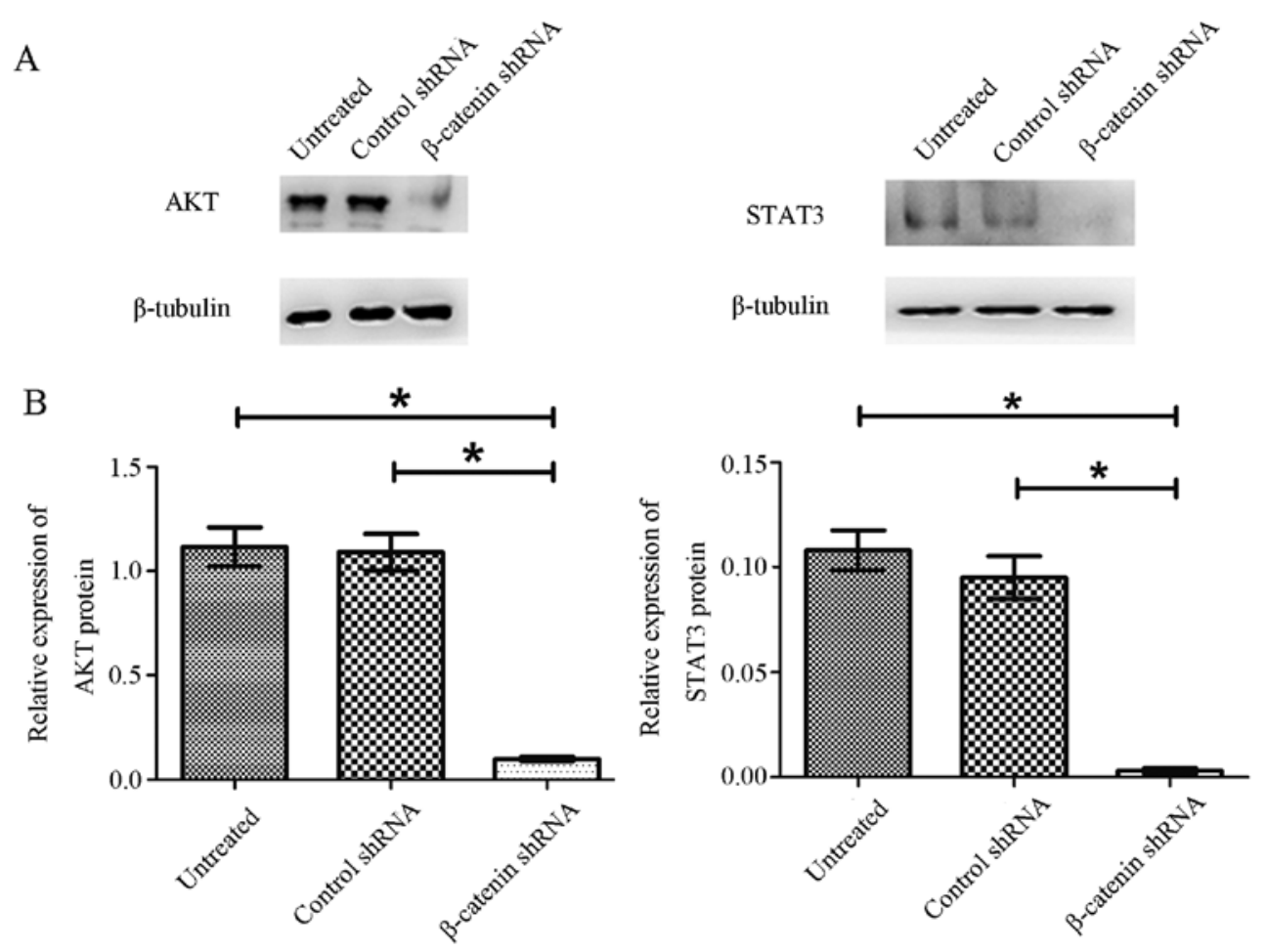

Figure 4. Knockdown of $\beta$-catenin inhibits the expression of AKT and STAT3 in GT1.1 cells. (A) Western blot analysis was used to assess AKT and STAT3 protein levels in GT1.1 cells. The bands of AKT (left panel) and STAT3 (right panel) protein in $\beta$-catenin shRNA-transfected cells were reduced compared to the other two groups while the loading control bands had no significant difference. As a loading control, the blots were stripped and reprobed with $\beta$-tubulin. (B) Compared with untreated and shRNA control cells, the relative protein levels of AKT (left panel) and STAT3 (right panel) were significantly reduced in $\beta$-catenin shRNA transfected cells. Data were expressed as mean $\pm \mathrm{SEM}, \mathrm{n}=3,{ }^{*} \mathrm{P}<0.05$ vs. untreated and control shRNA groups.

and invasion, we assessed the changes of the important signal molecules STAT3 and AKT in GT1.1 cells that critically promote tumor invasion and metastasis in various cancers $(25,26)$. Western blot analysis was performed to evaluate STAT3 and AKT proteins, and the data are shown in Fig. 4. Compared with control shRNA-transfected cells and untreated cells, both STAT3 and AKT protein levels were drastically reduced $(>90 \%)$ in $\beta$-catenin shRNA-transfected cells. These results demonstrated that knockdown of $\beta$-catenin inhibited the expression of STAT3 and AKT in pituitary adenoma cells.

Knockdown of $\beta$-catenin inhibits the expression of cyclin DI and CDK4 in GT1.1 cells. To further elucidate the growth suppression effect of $\beta$-catenin shRNA on GT1.1 cells, we assessed the changes of cyclin D1 and CDK4, two important cell cycle-related molecules, using western blot analysis. As shown in Fig. 5, $\beta$-catenin shRNA transfection downregulated cyclin D1 and CDK4 expression in GT1.1 cells in comparison to control shRNA. As expected, control shRNA had no effect on cyclin D1 and CDK4 compared to untreated cells. The results suggest that $\beta$-catenin may promote cell cycle progression to contribute to cell proliferation in GT1.1 cells.

Knockdown of $\beta$-catenin suppresses MMP-2 and MMP-9 expression in GT1.1 cells. MMP-2 and -9 are key gelatin proteolytic enzymes that break down and remodel the extracellular matrix to promote and facilitate cancer metastasis $(27,28)$. To study the mechanism of $\beta$-catenin knockdown on the inhibition of GT1.1 cell invasion, we quantified MMP-2 and MMP-9 mRNA expression in GT1.1 cells with RT-qPCR. The results showed that MMP-2 and MMP-9 mRNA expression were suppressed by 51 and $55 \%$ in $\beta$-catenin shRNA-transfected cells comparred to control shRNA (Fig. 6A). No significant difference was observed for either MMP-2 or MMP-9 mRNA levels between control shRNA group and untreated group. Gel gelatin zymography was performed to assess MMP-2 and MMP-9 protein levels. As shown in Fig. 6B, high levels of MMP-2 and MMP-9 were found in the supernatants of untreated GT1.1 cells, while no MMP-2 and -9 bands were detected when $\beta$-catenin was knocked down by shRNA. Apparently, the inhibitory effect of $\beta$-catenin shRNA on MMP-2/9 mRNA expression was less than that of MMP-2 and -9 secretions. We speculated that $\beta$-catenin shRNA might not only down-regulate MMP-2/9 expression (or synthesis) but also inhibits their secretion at extracellular MMP-2/9 levels. To test this possibility, we measured intracellular MMP-2/9 protein levels to see whether there was MMP-2/9 accumulation in the cells transfected with $\beta$-catenin shRNA. MMP-2 band was not detectable in the cellular extracts (Fig. 6B). There was a weak MMP-9 band detected in the cellular extracts of untreated cells and control shRNA-transfected cells, and no MMP-9 band was detected for $\beta$-catenin shRNA-transfected cells (Fig. 6B). These results suggested that $\beta$-catenin shRNA may reduce extracellular MMP-2/9 via interrupting MMP-2/9 synthesis rather than their secretion.

\section{Discussion}

In our previous study, we found that Wnt4 and its downstream gene $\beta$-catenin were overexpressed in FSH-omas, GH-omas, 
A
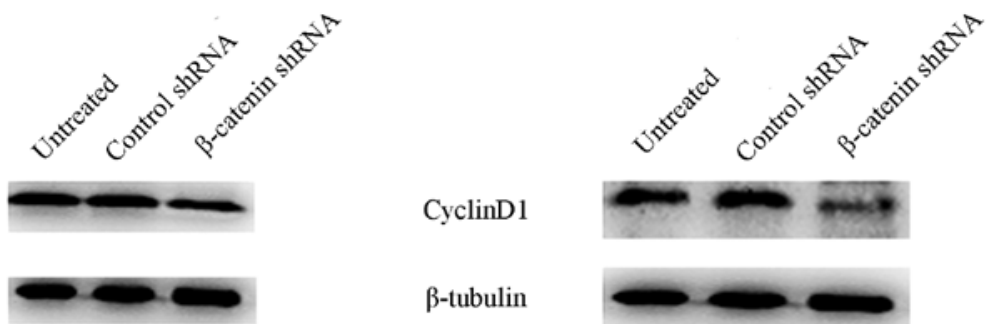

$\beta$-tubulin

CyclinD1

$\beta$-tubulin
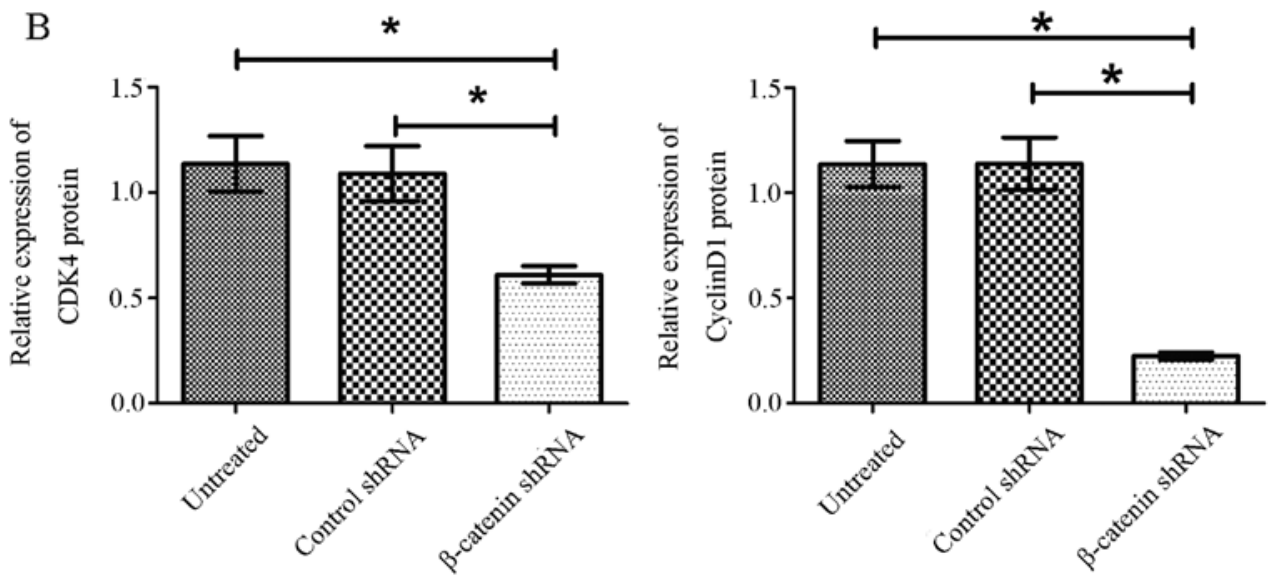

Figure 5. Knockdown of $\beta$-catenin inhibits the expression of cyclin D1 and CDK4 in GT1.1 cells. (A) Western blot was used to assess cyclin D1 and CDK4 protein levels in GT1.1 cells. The bands of CDK4 (left panel) and cyclin D1 (right panel) protein in $\beta$-catenin shRNA-transfected cells were reduced compared to the other two groups while the loading control bands had no significant difference. As a loading control, the blots were stripped and reprobed with $\beta$-tubulin. (B) Compared with untreated and shRNA control cells, the relative protein levels of CDK4 (left panel) and cyclin D1 (right panel) were significantly reduced in $\beta$-catenin shRNA transfected cells. Data were expressed as mean $\pm \mathrm{SEM}, \mathrm{n}=3,{ }^{*} \mathrm{P}<0.05$ vs. untreated and control shRNA groups.
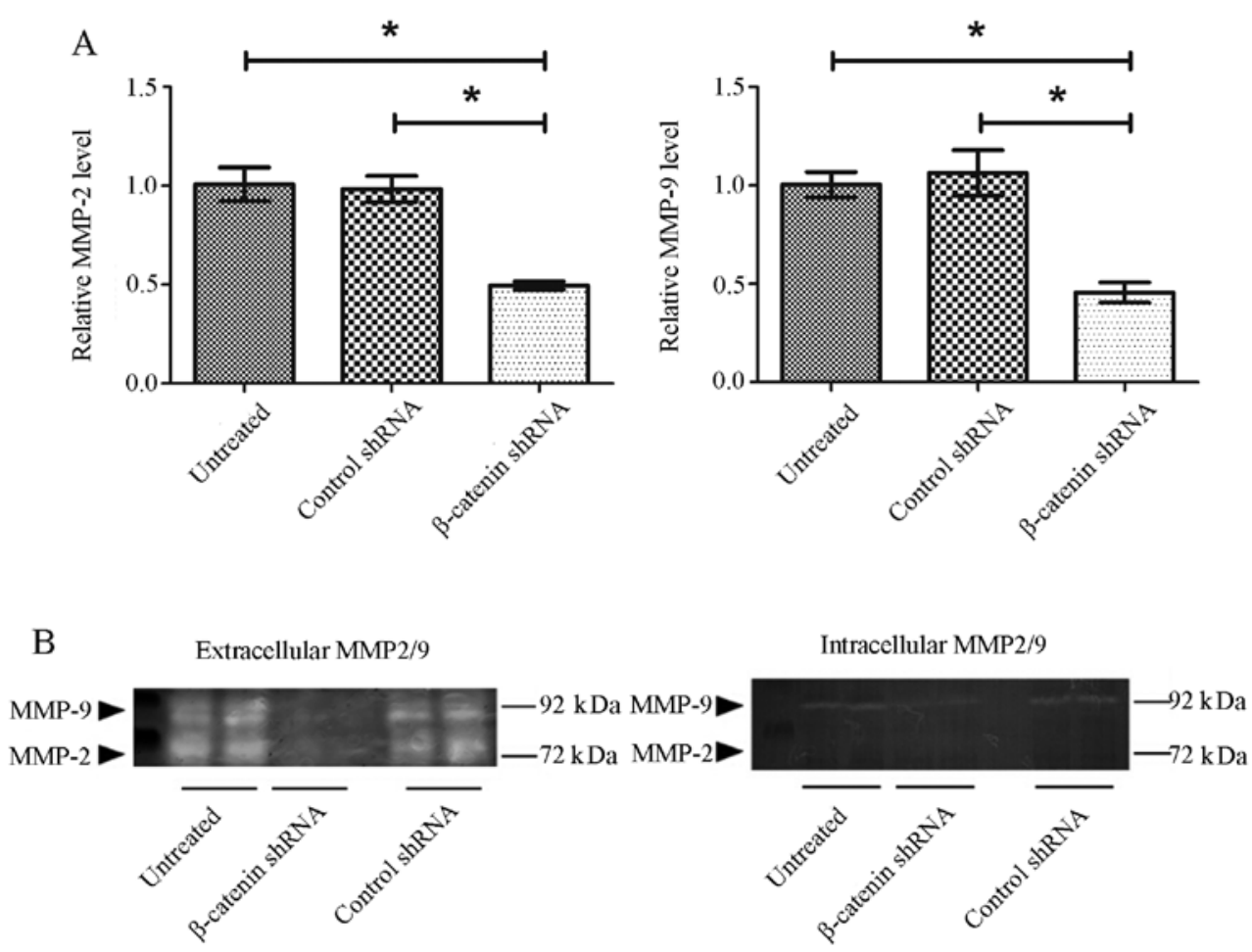

Figure 6. Knockdown of $\beta$-catenin with shRNA reduces MMP-2/9 levels in GT1.1 cells. (A) The mRNA transcription of MMP-2 (left panel) and MMP-9 (right panel) were significantly decreased in $\beta$-catenin shRNA transfected cells when compared with untreated and shRNA control cells. Data are expressed as mean \pm SEM, $n=3,{ }^{\circ} \mathrm{P}<0.05$ vs. untreated and control shRNA groups. (B) Knockdown of $\beta$-catenin dramatically suppressed extracellular MMP-2/9 levels (left panel). After GT1.1 cells were cultured in serum-free DMEM-F12 for $24 \mathrm{~h}$, a significant decrease was detected in the supernatants of $\beta$-catenin shRNA group on gelatin zymograms when compared with the shRNA control and untreated group. No MMP-2/9 bands of $\beta$-catenin shRNA group were seen on zymogram gels, while high levels of MMP-2 and MMP-9 were found in the supernatants of untreated and shRNA control GT1.1 cells. Intracellular MMP-9 protein level was also significantly decreased in $\beta$-catenin shRNA group (right panel). There was a weak MMP-9 band in the cellular extracts of untreated cells and control shRNA transfected cells, but no MMP-9 band for $\beta$-catenin shRNA existed in transfected cells. No MMP-2 band was detected in any group. 
PRL-omas, TSH-omas and NF-omas, but not in ACTH-omas. Moreover, the level of $\beta$-catenin expression was correlated with the degree of tumor invasion (14). However, the mechanisms underlying this correlation have not been established. In the present study, we showed that knockdown of $\beta$-catenin suppressed the proliferation and invasion of pituitary adenoma cells, and this change was accompanied by decreased expression of AKT, STAT3, cyclin D1, CDK4, MMP-2 and MMP-9. Our results suggest that $\beta$-catenin may regulate multiple downstream molecules to enhance pituitary adenoma cell proliferation and invasion.

Invasive pituitary adenomas that exhibit relatively higher mitotic activity with a MIB-1 labeling index (LI) $>3 \%$ or show extensive p53 immunoreactivity are classified as 'atypical adenomas' (29). The prognosis for invasive pituitary adenomas is often unpredictable because they are resistant to radiation and chemotherapy and cannot be fully resected. Currently, the mechanisms underlying the invasive phenotype of pituitary adenoma remain largely unknown. Deregulation of $\mathrm{Wnt} / \beta$-catenin pathway is involved in development and progression of various tumors. Here, our data showed that knocking down $\beta$-catenin by shRNA dramatically repressed the aggressive behavior of pituitary adenoma cells, i.e. proliferation and invasion.

AKT, also known as protein kinase B (PKB), plays a critical role in multiple cellular processes such as apoptosis, proliferation, transformation and migration. The activation of the PI3K/AKT pathway has been found in a wide range of cancers (30). AKT inhibition has been reported to decrease the expression of cyclin D1, MMP-2 and MMP-9, resulting in suppressed proliferation and invasion in U251 glioma cells (31). In the present study, we found that pituitary adenoma cell line GT1.1 expresses high level of AKT, and knockdown of $\beta$-catenin drastically ( $>90 \%$ ) inhibited AKT expression.

Besides AKT, STAT3 has also been reported to be a downstream molecule of the $\beta$-catenin pathway (32). STAT3 plays an important role in the proliferation of tumor cells by regulating cell cycle-related gene transcription (33-35). Of note, in this study, we found that knockdown of $\beta$-catenin almost completely blocked STAT3 expression in pituitary adenoma cells. STAT3 has been reported to act on cyclin D1 and CDK4 to promote cell proliferation (36), thus, we assessed the effect of $\beta$-catenin on cyclin D1 and CDK4. As expected, both proteins were downregulated in pituitary adenoma cells when $\beta$-catenin was knocked down by shRNA. These results suggest that the suppressed expression of AKT, STAT3, cyclin D1 and CDK 4 by $\beta$-catenin shRNA may account for the observed inhibition on the proliferation of pituitary adenoma cells.

Matrix metalloproteinases (MMPs) are a family of singlechain zinc-containing proteolytic enzymes that regulate the degradation of extracellular matrix in both physiological and pathological processes including angiogenesis, neoplasia and inflammation. Aberrant expression of MMPs has proved to contribute to tumor invasion and metastasis by breaking down and remodeling the extracellular matrix $(27,28)$. Several studies reported that there might be a possible correlation between invasive pituitary tumor phenotype and expression or activity of MMP-2 and MMP-9 $(37,38)$. In the present study, we showed that $\beta$-catenin shRNA transfection almost completely inhibited MMP-2/9 synthesis in pituitary adenoma cells, which may account for the reduced invasion of $\beta$-catenin shRNA transfected cells. It is worth pointing out that $\beta$-catenin shRNA inhibits MMP-2/9 mRNA expression to a lesser extent comparing its inhibition on MMP-2/9 protein synthesis. This discrepancy suggests that $\beta$-catenin may both inhibit MMP-2/9 transcription and translation, and further studies are warranted to investigate this possibility.

These in vitro data seem to be contradictory to our previous findings that $\beta$-catenin expression levels were reversely correlated with tumor grade in pituitary adenomas (14). However, in our previous study, we only compared $\beta$-catenin expression in invasive pituitary adenomas, but did not measure $\beta$-catenin levels in non-invasive pituitary adenomas. Using a stable $\beta$-catenin knockdown pituitary adenoma cell line, here we clearly showed that $\beta$-catenin contributes to pituitary adenoma cell proliferation and invasion.

In conclusion, the present study demonstrates that knockdown of $\beta$-catenin inhibits the proliferation and invasion of pituitary adenoma cells probably through inhibiting AKT, STAT3, cyclin D1, CDK4, MMP-2 and MMP-9, and targeting $\beta$-catenin signaling pathway might be a novel strategy for pituitary adenoma therapy.

\section{Acknowledgements}

This study was supported by grants from Shenzhen Science and Technology Innovation Commission (Shenzhen Key Laboratory of Neurosurgery - grant no. ZDSYS20140509173142601, and Basic Research Grant - grant no. JCYJ20130401113737900).

\section{References}

1. Vandeva S, Jaffrain-Rea ML, Daly AF, Tichomirowa M, Zacharieva S and Beckers A: The genetics of pituitary adenomas. Best Pract Res Clin Endocrinol Metab 24: 461-476, 2010.

2. Melmed S: Pathogenesis of pituitary tumors. Nat Rev Endocrinol 7: 257-266, 2011.

3. Asa SL and Ezzat S: The pathogenesis of pituitary tumors. Annu Rev Pathol 4: 97-126, 2009

4. Douglas KR, Brinkmeier ML, Kennell JA, et al: Identification of members of the Wnt signaling pathway in the embryonic pituitary gland. Mamm Genome 12: 843-851, 2001.

5. Brinkmeier ML, Potok MA, Cha KB, et al: TCF and Grouchorelated genes influence pituitary growth and development. Mol Endocrinol 17: 2152-2161, 2003.

6. Kioussi C, Briata P, Baek SH, et al: Identification of a Wnt/ Dvl/beta-Catenin $\rightarrow$ Pitx 2 pathway mediating cell-type-specific proliferation during development. Cell 111: 673-685, 2002.

7. Brinkmeier ML, Potok MA, Davis SW and Camper SA: TCF4 deficiency expands ventral diencephalon signaling and increases induction of pituitary progenitors. Dev Biol 311: 396-407, 2007

8. Zeng YA and Nusse R: Wnt proteins are self-renewal factors for mammary stem cells and promote their long-term expansion in culture. Cell Stem Cell 6: 568-577, 2010.

9. Polakis P: Wnt signaling and cancer. Genes Dev 14: 1837-1851, 2000.

10. Reed KR, Athineos D, Meniel VS, et al: B-catenin deficiency, but not Myc deletion, suppresses the immediate phenotypes of APC loss in the liver. Proc Natl Acad Sci USA 105: 18919-18923, 2008.

11. Nelson WJ and Nusse R: Convergence of Wnt, beta-catenin, and cadherin pathways. Science 303: 1483-1487, 2004.

12. Willert $\mathrm{K}$ and Jones KA: Wnt signaling: is the party in the nucleus? Genes Dev 20: 1394-1404, 2006.

13. Gaston-Massuet C, Andoniadou CL, Signore M, et al: Increased Wingless (Wnt) signaling in pituitary progenitor/stem cells gives rise to pituitary tumors in mice and humans. Proc Natl Acad Sci USA 108: 11482-11487, 2011. 
14. Li W, Zhang Y, Zhang M, Huang G and Zhang Q: Wnt4 is overexpressed in human pituitary adenomas and is associated with tumor invasion. J Clin Neurosci 21: 137-141, 2014.

15. Benjamin JM and Nelson WJ: Bench to bedside and back again: molecular mechanisms of alpha-catenin function and roles in tumorigenesis. Semin Cancer Biol 18: 53-64, 2008.

16. Kalani MY, Cheshier SH, Cord BJ, et al: Wnt-mediated selfrenewal of neural stem/progenitor cells. Proc Natl Acad Sci USA 105: 16970-16975, 2008.

17. Nusse R: Wnt signaling and stem cell control. Cell Res 18: 523-527, 2008.

18. Logan CY and Nusse R: The Wnt signaling pathway in development and disease. Annu RevCell Dev Biol 20: 781-810, 2004.

19. Cadigan KM and Peifer M: Wnt signaling from development to disease: insights from model systems. Cold Spring Harb Perspect Biol 1: a002881, 2009.

20. Park GB, Kim DJ, Kim YS, Lee HK, Kim CW and Hur DY: Silencing of galectin-3 represses osteosarcoma cell migration and invasion through inhibition of FAK/Src/Lyn activation and beta-catenin expression and increases susceptibility to chemotherapeutic agents. Int J Oncol 46: 185-194, 2015.

21. Bai XL, Zhang Q, Ye LY, et al: Myocyte enhancer factor $2 \mathrm{C}$ regulation of hepatocellular carcinoma via vascular endothelial growth factor and Wnt/beta-catenin signaling. Oncogene: Oct 20, 2014 (Epub ahead of print).

22. Salaroli R, Ronchi A, Buttarelli FR, et al: Wnt activation affects proliferation, invasiveness and radiosensitivity in medulloblastoma. J Neurooncol: Sep 28, 2014 (Epub ahead of print).

23. Gao ZH, Lu C, Wang MX, Han Y and Guo LJ: Differential beta-catenin expression levels are associated with morphological features and prognosis of colorectal cancer. Oncol Lett 8: 2069-2076, 2014.

24. Sareddy GR, Panigrahi M, Challa S, Mahadevan A and Babu PP: Activation of Wnt/beta-catenin/Tcf signaling pathway in human astrocytomas. Neurochem Int 55: 307-317, 2009.

25. Trovato M, Torre ML, Ragonese M, et al: HGF/c-met system targeting PI3K/AKT and STAT3/phosphorylated-STAT3 pathways in pituitary adenomas: an immunohistochemical characterization in view of targeted therapies. Endocrine 44: 735-743, 2013.

26. Ma PC, Tretiakova MS, Nallasura V, Jagadeeswaran $R$, Husain AN and Salgia R: Downstream signalling and specific inhibition of c-MET/HGF pathway in small cell lung cancer: implications for tumour invasion. Br J Cancer 97: 368-377, 2007.
27. Liotta LA and Kohn EC: The microenvironment of the tumourhost interface. Nature 411: 375-379, 2001.

28. Coussens LM and Werb Z: Inflammation and cancer. Nature 420: 860-867, 2002.

29. de Aguiar PH, Aires R, Laws ER, et al: Labeling index in pituitary adenomas evaluated by means of MIB-1: is there a prognostic role? A critical review. Neurol Res 32: 1060-1071, 2010.

30. Cully M, You H, Levine AJ and Mak TW: Beyond PTEN mutations: the PI3K pathway as an integrator of multiple inputs during tumorigenesis. Nat Rev Cancer 6: 184-192, 2006.

31. Fu Y, Zhang Q, Kang C, et al: Inhibitory effects of adenovirus mediated COX-2, Akt1 and PIK3R1 shRNA on the growth of malignant tumor cells in vitro and in vivo. Int J Oncol 35: 583-591, 2009.

32. Yue X, Lan F, Yang W, et al: Interruption of beta-catenin suppresses the EGFR pathway by blocking multiple oncogenic targets in human glioma cells. Brain Res 1366: 27-37, 2010.

33. Dechow TN, Pedranzini L, Leitch A, et al: Requirement of matrix metalloproteinase- 9 for the transformation of human mammary epithelial cells by Stat3-C. Proc Natl Acad Sci USA 101: 10602-10607, 2004.

34. Silver DL, Naora H, Liu J, Cheng W and Montell DJ: Activated signal transducer and activator of transcription (STAT) 3: localization in focal adhesions and function in ovarian cancer cell motility. Cancer Res 64: 3550-3558, 2004.

35. Senft C, Priester M, Polacin M, et al: Inhibition of the JAK-2/ STAT3 signaling pathway impedes the migratory and invasive potential of human glioblastoma cells. J Neurooncol 101: 393-403, 2011.

36. Wang J, Li X, Lu X and Pi L: The regulation of stat 3 signal transduction pathway to G1 to S phase of laryngocarcinoma cell. Lin Chung Er Bi Yan Hou Tou Jing Wai Ke Za Zhi 22: 699-703, 2008 (In Chinese).

37. Liu W, Kunishio K, Matsumoto Y, Okada M and Nagao S: Matrix metalloproteinase-2 expression correlates with cavernous sinus invasion in pituitary adenomas. J Clin Neurosci 12: 791-794, 2005.

38. Gong J, Zhao Y, Abdel-Fattah R, et al: Matrix metalloproteinase-9, a potential biological marker in invasive pituitary adenomas. Pituitary 11: 37-48, 2008. 